\title{
Blood pressure in rats: a comparison of a multifactorial experimental design to measurements in an outbred stock
}

\author{
D. BÜTTNER, ${ }^{1}$ H. HACKBARTH, F. WOLLNIK \& H. BORGGREVE \\ Institut für Versuchstierkunde im Zentralen Tierlaboratorium der Medizinischen Hochschule Hannover; \\ ${ }^{1}$ Zentrales Tierlaboratorium Universitätsklinikum der Gesamthochschule. Hufelandstr. 55, D-4300 Essen, \\ Federal Republic of Germany
}

\begin{abstract}
Summary
Systolic blood pressure was measured in males of 8 inbred strains and 1 outbred stock of rats 5 times over a period of $20 \mathrm{~min}$ on 5 consecutive days. The strain means ranged between $107.9 \mathrm{mmHg}$ and $149.3 \mathrm{mmHg}$. The estimated variance between strains $(\mathrm{V}=248.7 \mathrm{mmHg})$ was about 5 times higher than the variance within strains $(\mathrm{V}=54.3 \mathrm{mmHg})$. The intraindividual variance within strains was relatively constant $(\mathrm{V}=24.0-37.6 \mathrm{mmHg})$, while the interindividual variance varied to a great extent $(\mathrm{V}=4.5-44.5 \mathrm{mmHg}$ ) from strain to strain. The outbred stock showed values of blood pressure and components of variance similar to those of a single inbred strain. Thus, by investigation of a battery of 8 inbred strains in a multifactorial experimental design a greater phenotypic variability due to genetic strain differences is achieved than by measurements in a single outbred stock.
\end{abstract}

The variability within inbred strains represents exclusively the non-genetic variance component within as well as between animals. In contrast, the variability within an outbred stock should be caused by both the genetic and environmental components. This is the main justification for the use of outbred stocks in toxicological screening tests, where a wide range of phenotypes due to individual genetical differences is demanded. In contrast to this Festing (1979b) suggested sampling from several inbred strains in a multifactorial experimental design because a wider spread of phenotypes can be achieved than by sampling from a single inbred strain. Such a design should also give a wider range of phenotypes than sampling from an outbred stock.

There is evidence that the variability in systolic blood pressure between different inbred strains of rats is several times higher than within strains (Hansen, 1972). Some inbred strains of rats, such as SHR, WKY and GH (Okamoto, 1969; Phelan et al., 1972) are known to have been systematically selected for high or low blood pressure, while most other inbred strains are selected exclusively for criteria which are not directly linked to blood

Received 21 July 1983. Accepted 20 October 1983. pressure. The heritability of blood pressure in a broad sense was estimated by Tanase \& Suzuki (1971) to be $d^{2}=0 \cdot 64$. Little is known about the variability of blood pressure in outbred laboratory stocks.

The aim of the present study was to demonstrate that for blood pressure, sampling from several inbred strains gives a much broader spread of phenotypes due to genetical strain differences than sampling from a single outbred stock.

\section{Materials and methods \\ Animals}

Blood pressure was determined between the 125 th and 130th day of age in 6 males of each of the following 8 inbred strains of rats: $\mathrm{ACI} / \mathrm{Ztm}$, $\mathrm{AS} / \mathrm{Ztm}, \mathrm{BH} / \mathrm{Ztm}, \mathrm{BS} / \mathrm{Ztm}, \mathrm{DA} / \mathrm{Ztm}, \mathrm{LEW} / \mathrm{Ztm}$ (Festing, 1979a, b), MWF/Ztm (Hackbarth et al., 1980) and WC/Ztm (Gärtner, 1969). The animals were reared and kept under SPF conditions (barrier-maintained, free from infections listed by the Society of Laboratory Animal Science, 1977) in polycarbonate cages (Makrolon type III, $14 \times 26 \times 20 \mathrm{~cm})$. Room temperature was $22 \pm 2^{\circ} \mathrm{C}$, relative humidity $55 \pm 5 \%$, light from 7 a.m. -7 p.m. Pelleted food containing 19\% protein, $4 \%$ fat, $0.9 \%$ calcium, $0.7 \%$ phosphorus, and $0.2 \%$ sodium (Altromin 1324, Altromin International, Lage, FRG) and tap water from bottles were available ad libitum; wooden granules were used as bedding material.

10 days prior to the experiment the rats were transferred from the breeding unit and were kept individually in the animal room, where the measurements were performed. Each test group consisted of 6 animals of different strains which were selected randomly.

16 male Han: WIST rats were delivered from the Zentralinstitut für Versuchstiere in Hannover at 100-days-old. From their arrival they were kept under identical conditions to those of the inbred strains. The age of these animals at the beginning of test was 110 days for 6 animals, 117 days for another 6 animals and 124 days for 5 animals. 


\section{Blood pressure measurements}

Systolic blood pressure was measured in restrained conscious animals at $32^{\circ} \mathrm{C}$ room temperature with a Doppler ultrasonic method described in principle by Buñag (1973). For comparisons between direct and indirect measurements of arterial blood pressure see also Yamakoshi et al. (1979). 2 training periods were performed before the final measurements were started. The final blood pressure determinations were made on 5 consecutive days 5 times per session at $10,15,20,25$ and $30 \mathrm{~min}$ after being restrained by a wiremesh restraining tube and after being transferred to the preheated box at $32^{\circ} \mathrm{C}$.

\section{Results}

Means and standard deviations of blood pressure (BP) and bodyweight (BW) of the 8 inbred strains and the outbred Han: WIST stock as well as the mean of all inbred strains are listed in Table 1. The strains are ranked according to their blood pressure. $\mathrm{LEW} / \mathrm{Ztm}$ is the strain with the lowest blood pressure $(107.9 \mathrm{mmHg}), \mathrm{MWF} / \mathrm{Ztm}$ the strain with the highest blood pressure. The mean of all inbred strains is nearly identical to the mean of the Han: WIST stock $(126.6 \mathrm{mmHg}, 127.5 \mathrm{mmHg}$ respectively). The standard deviations within strains differ from 5.46 (WC/Ztm) to $9.40(\mathrm{BH} / \mathrm{Ztm})$, with the Han: WIST stock being in the middle of this range $(7.48 \mathrm{mmHg})$. Because of the large differences in blood pressure between the different inbred strains the standard deviation of all inbred rats (ignoring strains) was about twice as large as within a single inbred strain. All strain differences in mean blood pressure were significant at the $0.1 \%$ probability level according to Student's t-test with the exception of $\mathrm{WC} / \mathrm{Ztm}$ versus $\mathrm{DA} / \mathrm{Ztm}$ (n.s.) and $\mathrm{AS} / \mathrm{Ztm}$ versus $\mathrm{MWF} / \mathrm{Ztm}(P<5 \%)$.

Bodyweight varied from $245.0 \mathrm{~g}$ in the DA/Ztm strain to $387.5 \mathrm{~g}$ in the $\mathrm{LEW} / \mathrm{Ztm}$ strain. There was no correlation between blood pressure and bodyweight. An analysis of variance of blood pressure in a 3 -factor design with the factors of strain, between days and within days revealed highly significant differences between strains $(\mathrm{F}=690.88, \mathrm{DF}=7 ; 11, P<0.01)$ and interactions of strain and between days $(F=4.47, D F=28$; $112, P<0.01)$. There were no significant differences or trends within trials. In some strains (AS/Ztm, $\mathrm{BH} / \mathrm{Ztm}, \mathrm{WC} / \mathrm{Ztm}$ ) small but significant differences or trends from day to day existed. These interactions between strains and days were neglected for further calculation.

The components of variance between and within animals were compared separately for each strain (Table 2). Because the values are not totally normally distributed there is a slight difference of the sum of variances between and within animals compared to the total variance. Between $14.4 \%$ (WC/Ztm) and $62 \cdot 6 \%(\mathrm{DA} / \mathrm{Ztm})$ of the variability within strains is due to the variability between animals. The F-ratios of the variances between animals between DA and BH to WC are significant with $P<0.01$, those of LEW, BS, WIST and MWF to WC with $P<0.05$. The mean of all inbred strains $(49.8 \%)$ is close to the one of the outbred Han : WIST stock $(45 \cdot 0 \%)$.

An estimation of the components of variance within and between inbred strains by a 2 -factorial analysis of variance gives a variance between strains of $\mathrm{V}=248.74$, between animals of $\mathrm{V}=6.06$, between strains*animals of $V=23.34$ and a residual (within animals) of $V=29 \cdot 67$. These results are in good agreement with the results listed in Tables 1 and 2. Compared to the variability within strains, the variability between strains is about 5 times higher and differs therefore significantly from the variability within strains $(F=4.9$, $\mathrm{DF}=47.16, P<0.01)$.

The heritability in a broad sense estimated by a simple intraclass correlation (Festing, 1979) was $r_{1}=0.56$.

Discussion

The variation of systolic blcod pressure between

Table 1. Blood pressure (BP) and bodyweight (BW) (mean and SD) of different strains of rats

Mean of
BP

Means are ranked from low to high for blood pressure. 


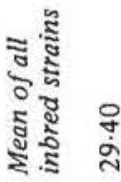

휴

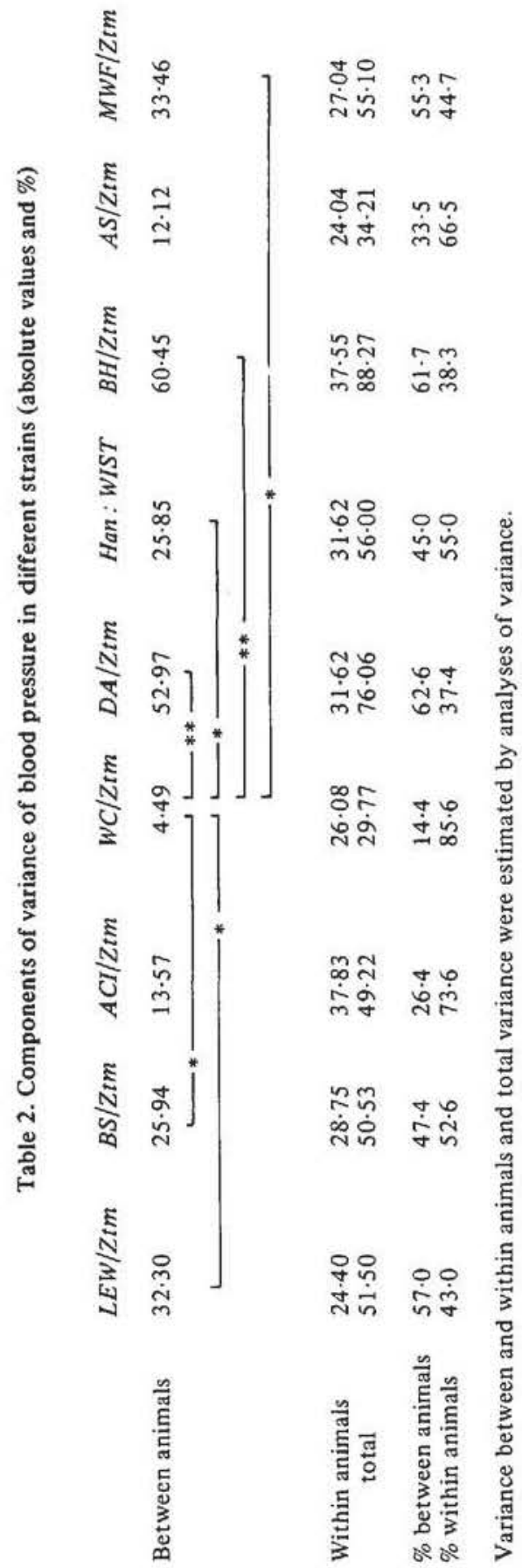


the strains used in the present study is in good agreement with the variance reported by Hansen (1972). Our results support his opinion, that inbred strains of rats, which are not selected for blood pressure, show a tendency to be distributed randomly. Hansen (1972) found the lowest systolic blood pressure in the $\mathrm{ACI} / \mathrm{N}$ strain (116 $\mathrm{mmHg}$ ) and the highest in the $\mathrm{OM} / \mathrm{N}$ strain (160 $\mathrm{mmHg}$ ) when the SHR/N strain, which has been selected for high blood pressure (Okamoto, 1969), is excluded. In our study the strain LEW/Ztm (108 $\mathrm{mmHg}$ ) had the lowest and the MWF/Ztm strain $(148 \mathrm{mmHg})$ the highest systolic blood pressure. Systolic blood pressure in the BS strain reported by Phelan et al. (1972) differs less than $1 \mathrm{mmHg}$ from our value. Moreover, the AS strain, which is closely related to the GH strain (Heslop \& Phelan, 1973) also shows a high blood pressure. These findings and nearly identical values of the ACI strain measured by Hansen (1972) and by us confirm the good reliability of the method used and show that sublines of inbred strains do not differ markedly in blood pressure. This variability between strains is comparable to that of human populations (Ambrosio et al., 1976; Brussard et al., 1981).

While within inbred strains the estimated variance between animals differs from $V=4.49$ in the strain WC to $\mathrm{V}=60.45$ in the $\mathrm{BH}$ strain, the variance within animals is relatively constant $(V=24 \cdot 04-37 \cdot 83)$. Only the strain WC differs significantly from others, but this may in part be due to the small number of animals/strain used in our study, but a genetic determination of the interindividual variance as suggested again by Hansen (1972) cannot be excluded. Such a genetic determination of variance within inbred strains has also been reported for several variables in rats and mice (Gärtner et al., 1976; 1978).

Standard deviations of systolic blood pressure from several different studies vary between 1 to 16 mmHg (Franklin et al., 1982; Yen et al., 1974, Orlov et al., 1982; Ten Berg, 1980; Rupp \& Jakob, 1981) independently of the genetic status of the animals used. Generally the standard deviations of different strains within one study do not differ to the same extent as the standard deviations between different studies. These differences are mainly due to differences in the experimental design as well as the different methods used, such as ambient temperatures during the measurements (Yen et al., 1978).

Although genetic theory proposes that outbred stocks should be more variable, the statistical demonstration of this requires large sample sizes due to the large sampling variance of a variable. Nevertheless, our findings do not support the hypothesis of a greater variation of blood pressure within outbred stocks in comparison to inbred strains. Yen et al. (1974) using well defined animals found nearly identical standard deviations within the outbred SDR stock as within the inbred WFR strain. This agrees with our finding, that the total variance within the outbred Han: WIST stock is nearly the same as the mean of the variances within the different inbred strains tested. Moreover, the components of variance between animals, within animals and the mean of systolic blood pressure are nearly identical. Thus, the outbred Han : WIST stock represents the mean of all inbred strains used in this study. The genetic variability of outbred stocks will differ according to their genetic history and amount of inbreeding. A possible screening of several outbred stocks may reveal stocks with higher variability. There is likely to be considerable overlap in the amount of intrastrain or stock variability. We have examined only a single outbred stock in this study, but on the basis of the data presented a single inbred strain gives a range of phenotypes as wide as in the Han : WIST outbred stock. Thus there is evidence that sampling from several inbred strains increases the variability to an amount which is not achieved within an outbred stock. Moreover such a multifactorial experimental design, as has also been suggested for toxicological screening (Festing, 1979), allows a clear separation of genetic effects from others and makes experiments repeatable even after several years.

\section{Acknowledgements}

The authors thank Mrs S. Lühmann for skilful technical assistance in this project. The work was supported by a grant from Deutsche Forschungsgemeinschaft (SFB 146).

\section{References}

Ambrosio, G. B., Bugaro, L., Gabaldo, S., Pigato, R., Zamboni, S. \& Dal Palù, C. (1976). Blood pressure and its spontaneous variations in a northern Italian population. Clinical Science and Molecular Medicine 51, 669-671.
Brussaard, J. H., van Raaij, J. M. A., Stasse-Wolthuis, M., Katan, M. B. \& Hautvast, J. G. A. J. (1981). Blood pressure and diet in normotensive volunteers: absence of an effect of dietary fiber, protein, or fat. American Journal of Clinical Nutrition 34, 2023-2029. 
Buñag, R. D. (1973). Validation of a tail-cuff method for measuring systolic pressure. Journal of Applied Physiology 34, 279-283.

Festing, M. F. W. (1979a). Inbred Strains in Biomedical Research. London: Macmillan.

Festing, M. F. W. (1979b). Properties of inbred strains and outbred stocks, with special reference to toxicity testing. Journal of Toxicology and Environmental Health 5, 53-68.

Franklin, T. J., Morris, W. P. \& Loveday, B. E. (1982). Effects of inhibitors of collagen maturation on hypertension in rats. Blood Vessels 19, 217-225.

Gärtner, K. (1969). Heriditärer Kryptorchismus bei Wistarratten. Zeitschrift für Versuchstierkunde 11, 179-189.

Gärtner, K., Bube, P., Flamme, A., Peters, K. \& Pfaff, J. (1976). Komponenten biologischer Variabilität und die Grenzen ihrer Manipulierbarkeit. Zeitschrift für Versuchstierkunde 18, 146-158.

Gärtner, K., Treiber, A., Friedel, R., Doehler, K. D., Messow, C. \& Trautschold, I. (1978). Die Hauptursachen biologisch bedingter Streuungen quantitativer Merkmale bei Versuchstieren. Deutsche Tierärztliche Wochenschrift 85, 245-248.

Hackbarth, H., Gärtner, K., Alt, J. M. \& Stolte, H. (1980). A subline of the Munich Wistar (MW) strain, response to selection for surface glomeruli. Rat News Letter 7 , 23.

Hansen, C. T. (1972). A genetic ảnalysis of hypertension in the rat. In Spontaneous Hypertension (ed. K. Okamoto), Berlin: Springer.

Heslop, B. F. \& Phelan, E. L. (1973). The GH and AS hypertensive rat strains. Laboratory Animals 7, 4146.

Okamoto, K. (1969). Spontaneous hypertension in rats. In International Review of Experimental Pathology, Vol. 7 (eds G. W. Richter \& M. A. Epstein), pp. 227270. New York: Academic Press.
Orlov, S. N., Gulak, P. V., Litvinov, I. S. \& Postnov, Y. V. (1982). Evidence of altered structure of the erythrocyte membrane in spontaneously hypertensive rats. Clinical Science 63, 43-45.

Phelan, E. L., Clark, D. W., Gresson, C. R. \& Jones, D. R. (1972). The development and inheritance of high blood pressure in the New Zealand strain of rats with genetic hypertension. In Spontaneous Hypertension (ed. K. Okamoto), Berlin: Springer.

Rupp, H. \& Jacob, R. (1981). Response of blood pressure and cardiac myosin polymorphism to swimming training in the spontaneously hypertensive rat. Canadian Journal of Physiology and Pharmacology 60, 10981103.

Society of Laboratory Animal Science (1977). Liste der Erreger zur Spezifizierung bei SPF-Versuchstieren. Veröffentlichung der Gesellschaft für Versuchstier. kunde 2.

Tanase, H. \& Suzuki, Y. (1971). Strain difference and genetic determination of blood pressure in rats. Experimental Animals 20,1-5.

Ten Berg, R. G. M. \& de Jong, W. (1980). Increase in plasma renin activity, water intake and blood pressure following application and reapplication of an artery clip. Pflügers Archiv 385, 211-215.

Yamakoshi, K.-H., Shimazu, H. \& Togawa, T. (1979). Indirect measurement of instantaneous arterial blood pressure in the rat. American Journal of Physiology 237, H632-H637.

Yen, T. T., Yu, P. L., Roeder, H. \& Willard, P. W. (1974). A genetic study of hypertension in Okamoto-Aoki spontaneously hypertensive rats. Heredity 33, 309316.

Yen, T. T., Pearson, D. V., Powell, C. E. \& Krischner, G. L. (1978). Thermal stress elevates the systolic blood pressure of spontaneously hypertensive rats. Life Science 22, 359-362.

Blutdruck bei Ratten: ein Vergleich eines mehrfaktoriellen Versuchsansatzes zu Messungen in einem Auszuchtsamm

\section{BÜTTNER, H. HACKBARTH, F. WOLLNIK \& H. BORGGREVE}

\section{Zusammenfassung}

An männlichen Ratten von acht Inzuchtstämmen und einem Auszuchtstamm wurde der systolische Blutdruck an fünf aufeinanderfolgenden Tagen jeweils $5 \mathrm{mal}$ über einen Zeitraum von 20 Minuten gemessen.

Die Stammesmittelwerte lagen zwischen $107.9 \mathrm{mmHg}$ und $149.3 \mathrm{mmHg}$. Die geschäzte Varianz zwischen den Stämmen war mit $\mathrm{S}=248.7 \mathrm{mmHg}$ etwa fünfmal größer als die mittlere Varianz innerhalb der Stämme $(S=54 \cdot 3$ $\mathrm{mmHg}$ ).

Die intra-individuelle Varianz innerhalb der Stämme (V $=24.04-37.55 \mathrm{mmHg}$ ) war relativ konstant, während die inter-individuelle Varianz zwischen $\mathrm{V}=4 \cdot 5-44.5$ I $\mathrm{mmHg}$ je nach Stamm schwankte.

Der Auszuchstamm zeigte Blutdruckwerte und vor allem Varianzkomponenten die vergleichbar waren mit denen eines einzelnen Inzuchstammes.

So daß durch Untersuchungen einer Batterie von acht Inzuchtstämmen in einem mehrfaktoriellen Versuchsansatz eine größere phänotypische Variabilität auf Grund genetischer Stammesunterschiede erreicht wird als durch Messungen eines einzelnen Auszuchtstammes. 